Research Article

\title{
Comparison of efficacy and safety of adapalene and benzoyl peroxide- clindamycin combination in the topical treatment of acne vulgaris
}

\author{
Anuradha Dubey ${ }^{1}$, Hanmant Amane ${ }^{2}$
}

\author{
${ }^{1}$ Department of Pharmacology, \\ L. N. Medical College and \\ Research Center, Bhopal, \\ Madhya Pradesh, India \\ ${ }^{2}$ Department of Pharmacology, \\ G. M. E. R. S. Medical College, \\ Junagadh, Gujarat, India
}

Received: 11 September 2016 Accepted: 21 September 2016

\section{*Correspondence to: \\ Dr. Anuradha Dubey, \\ Email: dranudubey999@ \\ gmail.com}

Copyright: (C) the author(s), publisher and licensee Medip Academy. This is an openaccess article distributed under the terms of the Creative Commons Attribution NonCommercial License, which permits unrestricted noncommercial use, distribution, and reproduction in any medium, provided the original work is properly cited.

\begin{abstract}
Background: Acne vulgaris is a dermatological disorder characterised by formation of comedones and inflammatory lesions. The treatment of acne basically involves reduction of lesions and prevention of permanent scarring. The current line of treatment for mild to moderate acne is topical medications with antimicrobials and retinoids. The present study assessed the efficacy and safety of adapalene in comparison to benzoyl peroxide-clindamycin combination that whether it is better than the benzoyl peroxide-clindamycin combination for topical treatment of mild to moderate acne vulgaris.

Methods: In this study, the patients with mild to moderate acne vulgaris were divided into two groups, one group was treated with topical adapalene whereas topical benzoyl peroxide-clindamycin combination was given to the other group. Assessment of efficacy was done by total lesion counting while safety assessment was done by noting the adverse drug reactions due to medication, the results were compared at the end of 1,2 and 3 months with the baseline values.

Results: At the end of this study, it was found that the reduction of noninflammatory, inflammatory and total lesion counts from baseline were highly significant in both the groups $(\mathrm{p}<0.0001)$, but between the groups, differences were not significant statistically ( $p>0.05)$, therefore adapalene and benzoyl peroxide-clindamycin combination were found to have similar efficacy. The tolerability profile of adapalene was comparatively better than benzoyl peroxide-clindamycin combination.

Conclusions: Adapalene is as efficacious as benzoyl peroxide-clindamycin combination to treat mild to moderate acne vulgaris, but it is comparatively better tolerated than benzoyl peroxide-clindamycin combination.
\end{abstract}

Keywords: Pilo-sebaceous unit, Comedones, Antimicrobials, Retinoids

\section{INTRODUCTION}

Acne vulgaris is a dermatological disorder of the pilosebaceous unit that affects majority of people at sometimes during their life. Adolescence is the usual period when people are affected with acne, but it can also persist during adult age. ${ }^{1}$ Because of the involvement of face and associated cosmetic problems, acne patients are at increased risk of anxiety and depression which affects their quality of life. ${ }^{2}$ The characteristic lesions in acne are called comedones which are actually the noninflammatory lesions whereas the inflammatory lesions are papules, pustules and nodules. ${ }^{3}$
For the treatment of mild and moderate acne vulgaris, there are many topical drugs available like benzoyl peroxide, antibiotics and retinoids, which can be used alone, or in combination. ${ }^{4}$ Benzoyl peroxide is one of the commonly used antimicrobial which is a potent antibacterial, mild anti-inflammatory and comedolytic. It can be utilized as monotherapy, or can be used along with topical antibiotics or topical retinoids in acne treatment. ${ }^{5}$ Clindamycin is a lincosamide antibiotic which inhibits the bacterial protein synthesis by interfering with ribosomal translocation. ${ }^{3}$ If clindamycin is combined with 
benzoyl peroxide, it leads to additive effects and also the combination is well-tolerated. ${ }^{5}$

Adapalene is a newer retinoid which has been derived from naphthoic acid. It is an agonist on the retinoid receptors and benefits the acne patients by inhibiting the keratinization and inflammation. It has lesser problem of causing irritation and shows better patient compliance because it binds to only selective subtypes of retinoic acid receptors. Also another advantage of adapalene is that it can be combined with other topical drugs for acne treatment, without causing significant side effects. ${ }^{6}$ The main objective of the present study was to assess the efficacy and safety of adapalene in comparison to benzoyl peroxide-clindamycin combination for the treatment of mild to moderate acne vulgaris.

\section{METHODS}

A prospective and randomized study was conducted from November 2012 to April 2014 including the acne patients who attended the dermatology OPD at a tertiary care hospital in Bhopal. It was an observational, comparative and open-label study in which male and female patients in the age group of 12 to 30 years were enrolled.

The ethical clearance was obtained from the research advisory committee and Institutional Ethics committee. The study was started after obtaining written informed consent from each patient.

The grading of acne was done by a simple grading system which divides the acne into four grades. ${ }^{7}$

- Grade 1: Comedones, occasional papules

- Grade 2: Papules, comedones, few pustules

- Grade 3: Predominant pustules, nodules, abscesses

- Grade 4: Mainly cysts, abscesses, widespread scarring.

The patients only with mild to moderate (grade 1 and 2) acne vulgaris were included in the study. A total of 100 patients who attended dermatology OPD for acne treatment were selected and randomly divided into two groups, with 50 patients in group $\mathrm{A}$ and 50 patients in group B. The patients in the group A received adapalene $(0.1 \%)$, while benzoyl peroxide $(2.5 \%)$ clindamycin $(1 \%)$ combination was given to the group B patients. All the drugs were provided in the gel form. The patients had been instructed to apply a thin film of gel on the whole affected area, once daily at bed time.

\section{Inclusion criteria}

- The male patients and non-pregnant female patients of age between 12-30 years.

- The patients with only comedones as noninflammatory lesions, and papules and pustules as inflammatory lesions were included in the study (mild to moderate acne vulgaris- grades 1 and 2).

\section{Exclusion criteria}

- The patients with acne vulgaris, of age less than 12 years, or greater than 30 years, and the pregnant women were excluded from the study

- Presence of severe inflammatory lesions of acne like nodulo-cystic lesions (grades 3 and 4)

- Use of any other drug for the treatment of acne vulgaris within 1 month.

\section{Materials}

- Patients with acne after evaluating above criteria

- $0.1 \%$ Adapalene gel

- $2.5 \%$ benzoyl peroxide $-1 \%$ clindamycin gel

\section{Methodology}

\section{Efficacy assessment}

The efficacy assessment of the patients was done by total lesion counting (TLC). 8 The change of total lesion, both inflammatory and non-inflammatory lesions, count from baseline was the main efficacy parameter.

\section{Safety assessment}

The safety assessment at each visit was done by noting the erythema, scaling, dryness, pain, tenderness, and pruritus as safety parameters. Any other adverse effect encountered during treatment was noted.

Findings during the basal evaluation were noted in the chart that was made and maintained for each patient. Patients attended the hospital at the end of 1, 2, and 3 months after the start of treatment for monitoring the efficacy and safety of the drugs.

At each visit, the number of inflammatory (papules, pustules) and non-inflammatory (comedones) acne lesions on the face, upper part of chest and back were counted, and adverse event, if any, developed were recorded.

\section{Statistical analysis}

The descriptive statistics (mean and standard deviation) were calculated for non-inflammatory, inflammatory and total lesion counts at each post-baseline visit for both the treatment groups. The changes in the lesion counts were analysed by one way analysis of variance in both the groups, whereas for the analysis of lesion counts in between the groups, the unpaired student $t$ test was used.

All the statistical tests had the significance probability level set at 0.05 . For the safety analysis, the adverse event data were summarized by graphical representation, but no statistical analysis was performed. 


\section{RESULTS}

A total of 100 patients were enrolled in this study, out of which 47 patients completed the treatment in group A whereas 46 completed it in group B, during the study period. Three patients from group A and four patients from group B discontinued the treatment early and dropped out of the study for various reasons like noncompliance, request of the patient, and lost to follow-up.

\section{Demographic details}

Table 1: Distribution of acne patients based on age of the patient.

\begin{tabular}{|ll|}
\hline Age (In years) & Number of patients $(\mathbf{n}=\mathbf{9 3})$ \\
\hline $12-15$ & 6 \\
\hline $16-19$ & 30 \\
\hline $20-23$ & 30 \\
\hline $24-27$ & 15 \\
\hline $28-31$ & 12 \\
\hline
\end{tabular}

Table 2: Distribution of acne patients based on gender of the patient.

\begin{tabular}{|ll|}
\hline Gender & Number of patients $(\%)$ \\
\hline Male & $38(40.86 \%)$ \\
\hline Female & $55(59.13 \%)$ \\
\hline
\end{tabular}

Table 3: Distribution of patients of acne based on grade of acne.

\begin{tabular}{|ll|}
\hline Grade of Acne & Number of patients (\%) \\
\hline Grade I & $30(32.25 \%)$ \\
\hline Grade II & $63(67.74 \%)$ \\
\hline
\end{tabular}

\section{Efficacy assessment}

Table 4: Comparison of non-inflammatory lesions before and after the treatment.

\begin{tabular}{|lllll|}
\hline \multirow{2}{*}{ Lesions } & \multicolumn{2}{l}{$\begin{array}{l}\text { Adapalene group } \\
\text { (A) }\end{array}$} & \multicolumn{2}{l|}{$\begin{array}{l}\text { Benzoyl peroxide - } \\
\text { clindamycin group (B) }\end{array}$} \\
\cline { 2 - 5 } & Baseline & $\begin{array}{l}\text { After 3 } \\
\text { months }\end{array}$ & Baseline & $\begin{array}{l}\text { After 3 } \\
\text { months }\end{array}$ \\
\hline NIL & 1218 & 186 & 1163 & 246 \\
\hline
\end{tabular}

Baseline $=0$ month; After 3 months $=$ End of therapy

Table 5: Comparison of inflammatory lesions before and after the treatment.

\begin{tabular}{|lllll|}
\hline Lesions & $\begin{array}{l}\text { Adapalene } \\
\text { group (A) }\end{array}$ & \multicolumn{3}{c|}{$\begin{array}{l}\text { Benzoyl peroxide - } \\
\text { clindamycin group (B) }\end{array}$} \\
\cline { 2 - 5 } & Baseline & $\begin{array}{l}\text { After 3 } \\
\text { months }\end{array}$ & Baseline & $\begin{array}{l}\text { After 3 } \\
\text { months }\end{array}$ \\
\hline IL & 130 & 16 & 131 & 17 \\
\hline
\end{tabular}

Baseline $=0$ month, After 3 months $=$ End of therapy
Table 6: Comparison of total lesions before and after the treatment.

\begin{tabular}{|c|c|c|c|c|}
\hline \multirow{2}{*}{ Lesions } & \multicolumn{2}{|c|}{$\begin{array}{l}\text { Adapalene group } \\
\text { (A) }\end{array}$} & \multicolumn{2}{|c|}{$\begin{array}{l}\text { Benzoyl peroxide- } \\
\text { clindamycin group (B) }\end{array}$} \\
\hline & Bas & $\begin{array}{l}\text { After } 3 \\
\text { months }\end{array}$ & Baseline & $\begin{array}{l}\text { After } 3 \\
\text { months }\end{array}$ \\
\hline Total & 1348 & 202 & 1294 & 263 \\
\hline
\end{tabular}

Baseline $=0$ month, After 3 months $=$ End of therapy

In group $\mathrm{A}$, the mean count of non-inflammatory lesions was 25.91 at the first visit (baseline), which was reduced to $16.78,9.7$ and 3.95 at the end of one, two and three months respectively. The mean count of inflammatory lesions was 16.25 at the first visit, which was reduced to $10.25,5.37$ and 2 at the end of one, two and three months respectively, whereas the mean count of total lesions was 28.68 during the first visit, which was reduced to 18.5 , 10.68 and 4.29 at the end of one, two and three months respectively (Figure 1).

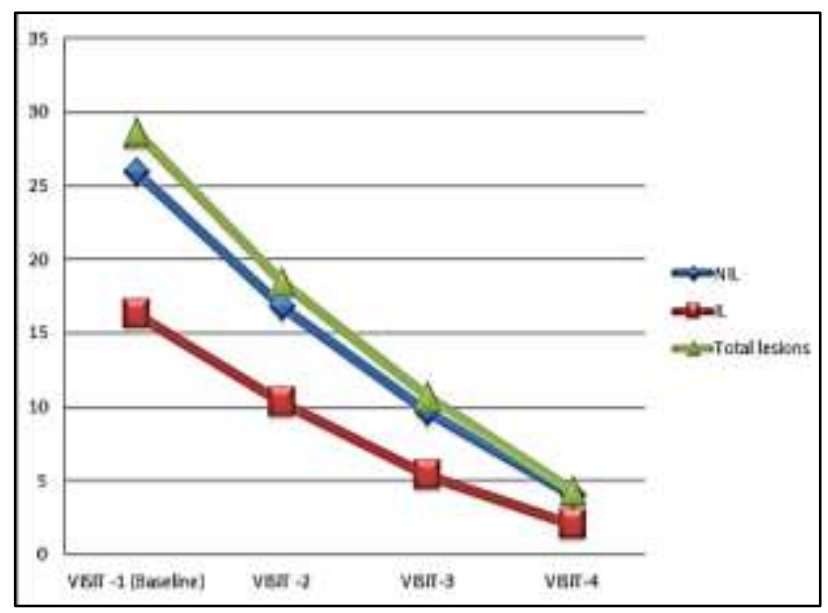

Figure 1: Reduction of lesions in adapalene group (A group).

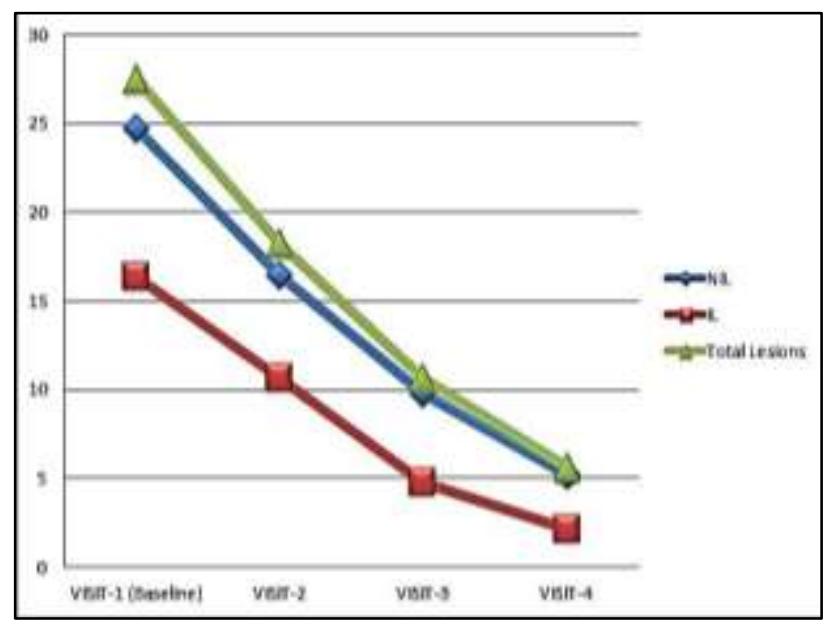

Figure 2: Reduction of lesions in benzoyl peroxideclindamycin group (B group). 
In group B, it was found that the mean count of noninflammatory lesions was 24.74 at the first visit (baseline), which was reduced to $16.46,9.82$ and 5.23 at the end of one, two and three months respectively. The mean count of inflammatory lesions was 16.38 at the first visit, which was reduced to $10.62,4.75$ and 2.12 at the end of one, two and three months respectively, whereas the mean count of total lesions was 27.53 at the first visit, which was reduced to $18.27,10.63$ and 5.59 at the end of one, two and three months respectively (Figure 2).
Reduction of non-inflammatory lesion, inflammatory lesion and total lesion counts from baseline values were highly significant in both the groups $(\mathrm{p}<0.0001)$.

In non-inflammatory lesions, there was statistically significant difference present in different visits $(p<0.0001)$ in both the groups, but between the groups, there was no significant difference in different visits $(\mathrm{p}>0.05)$ (Table 7).

Table 7: Percentage of reduction in non-inflammatory lesions.

\begin{tabular}{|lllll|} 
Visits & Visit-1 (Baseline) & Visit-2 & Visit-3 & Visit-4 \\
\hline Group A & 0 & $37.25 \pm 11.63$ & $65.35 \pm 15.66$ & $87 \pm 12.33$ \\
\hline Group B & 0 & $35.74 \pm 10.85$ & $64.85 \pm 16.85$ & $83.17 \pm 15.97$ \\
\hline
\end{tabular}

Table 8: Percentage of reduction in inflammatory lesions.

\begin{tabular}{|ll|lll|}
\hline Visits & Visit-1 (Baseline) & Visit-2 & Visit-3 & Visit-4 \\
\hline Group A & 0 & $37.53 \pm 8.05$ & $67.23 \pm 7.45$ & $87.6 \pm 1.02$ \\
\hline Group B & 0 & $36.46 \pm 11.97$ & $71.73 \pm 6.99$ & $87.12 \pm 1.03$ \\
\hline
\end{tabular}

Table 9: Percentage of reduction in total lesions.

\begin{tabular}{|lllll|}
\hline Visits & Visit-1 (Baseline) & Visit-2 & Visit-3 & Visit-4 \\
\hline Group A & 0 & $37.70 \pm 10.98$ & $66.13 \pm 14.85$ & $87.9 \pm 10.7$ \\
\hline Group B & 0 & $36.08 \pm 10.55$ & $65.77 \pm 15.90$ & $83.89 \pm 15.13$ \\
\hline
\end{tabular}

In inflammatory lesions, there was significant difference in different visits $(\mathrm{p}<0.0001)$ in both the groups, but between the groups, there was no significant difference between baseline lesions and lesions at the end of 1 month ( $p>0.05)$, whereas a statistically significant difference was observed in lesions at the end of 2 months and 3 months $(\mathrm{p}<0.05)$ (Table 8).

\section{Safety assessment}

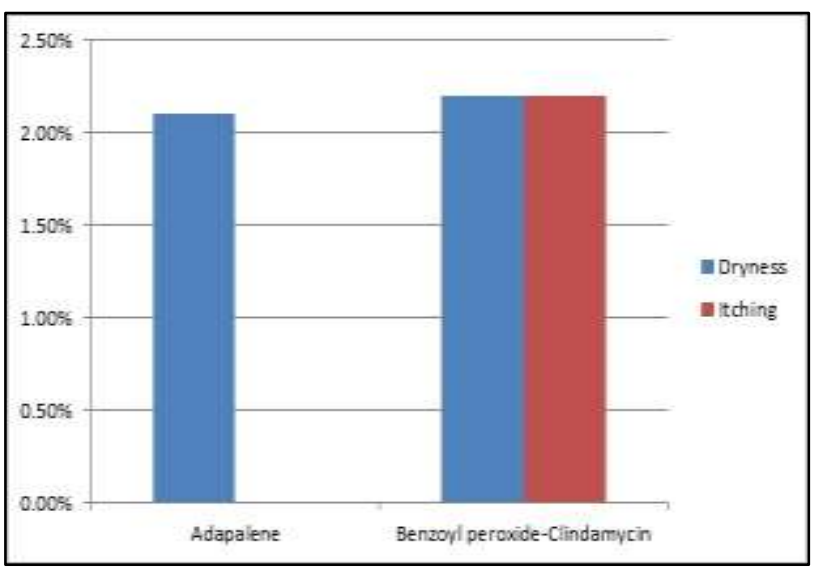

Figure 3: Adverse drug reactions (ADR).
In total lesions, there was statistically significant difference present in different visits $(p<0.0001)$ in both the groups, but between the groups, there was no significant difference in different visits $(\mathrm{p}>0.05)$ (Table 9).

In the present study, adapalene showed better safety profile than benzoyl peroxide-clindamycin combination, there was only the problem of dryness which was seen in $2.1 \%$ patients treated with adapalene, whereas the patients who were prescribed benzoyl peroxide-clindamycin combination were affected with both dryness $(2.2 \%)$ and itching (2.2\%). Adverse events did not interfere with completion of treatment in the patients (Figure 3).

\section{Figure legends}

$\mathrm{NIL}=$ Non-inflammatory lesions, IL= Inflammatory lesions, VISIT-1= Baseline values, VISIT-2= At the end of 1 month, VISIT-3= At the end of 2 months, VISIT-4= At the end of 3 months.

\section{DISCUSSION}

Acne vulgaris is an inflammatory disorder of pilosebaceous unit which occurs as a result of follicular 
epidermal hyperproliferation, increased sebum production, microbial flora changes and inflammation. The influence of androgen, P. acnes infection, some medications, genetic causes and stress are the main factors responsible for acne development. ${ }^{9}$ Comedones are the characteristic lesions of acne which constitute the noninflammatory lesions, whereas papules, pustules and nodules are the inflammatory acne lesions. ${ }^{3}$ As far as treatment is concerned, topical therapy is the standard treatment for mild to moderate acne vulgaris. ${ }^{4}$ Systemic therapy is indicated in the severe cases of acne vulgaris. ${ }^{8}$ The topical therapies of choice are retinoids and antimicrobials, such as benzoyl peroxide and antibiotics. Topical retinoids, by acting on follicular keratinocytes, prevent the excessive cornification and follicular blockage, and also decrease the release of inflammatory cytokines. ${ }^{10}$ Benzoyl peroxide and antibiotics are the topical antimicrobials which have efficacy in treating inflammatory acne. ${ }^{10}$

One of the novel retinoid is adapalene which has efficacy in the topical treatment of acne vulgaris as shown in some studies. ${ }^{6,11,12}$ It is a derivative of naphthoic acid and has retinoid receptor agonistic activity. It inhibits keratinization and has anti-inflammatory activity. ${ }^{6}$ The comparative studies have demonstrated better cutaneous safety of adapalene than the various formulations (gel, cream and microsphere gel) of tretinoin as well as isotretinoin gel. ${ }^{13-16}$

This study was undertaken to compare the efficacy and safety of adapalene and benzoyl peroxide-clindamycin combination for the topical treatment of mild to moderate acne vulgaris. It was observed that at the end of 3 months, group A (adapalene) patients showed $87 \%$ mean reduction in non-inflammatory lesions, $87.6 \%$ mean reduction in inflammatory lesions, whereas $87.9 \%$ mean reduction in total lesion counts. This data correlates with the study conducted by Persy SH in 2003, which demonstrated that 96\% patients showed an improvement in their acne from baseline. Unlike our study, this study was a multi-centre, non-comparative study of Adapalene gel $0.1 \%$, conducted in 21 centres across India, in patients of mild to moderate acne vulgaris. 6

In our study, the effects of adapalene and benzoyl peroxide-clindamycin combination were compared in the topical treatment of mild to moderate acne vulgaris and it was found that there was no statistical significant difference $(p>0.05)$ in efficacy between groups A (adapalene) and B (benzoyl peroxide-clindamycin) which implies adapalene has similar efficacy as benzoyl peroxide-clindamycin combination. In a similar study conducted by Ghoshal L et al, the effects of adapalene and azithromycin, given separately and in combination, on non-inflammatory and inflammatory lesions were compared and it was concluded that adapalene was superior to other two groups in reducing noninflammatory lesions. These findings were correlated with our study, but there was no statistically significant difference in the efficacy of three treatment groups in the inflammatory lesions of acne. This difference is might be due to inclusion of severe inflammatory acne lesions and use of azithromycin instead of clindamycin in the study conducted by Ghoshal L et al. ${ }^{17}$

In yet another study conducted by Langner et al, it has been concluded that benzoyl peroxide-clindamycin combination and adapalene are both effective treatments for acne which is in accordance with our study, but benzoyl peroxide-clindamycin combination was found to have a significantly earlier onset of action, and was significantly more effective against inflammatory and total lesions. ${ }^{18}$

It has also been shown that use of nano-emulsion gel formulation of adapalene and clindamycin combination was found to have better efficacy and safety than its conventional formulation for the treatment of acne vulgaris in a study conducted by Prasad $\mathrm{S}$ et al. ${ }^{12}$

Further, adapalene acts as a penetration enhancer and increases the penetration of topical clindamycin phosphate, therefore it can be said that application of clindamycin phosphate gel after the pre-treatment of skin with adapalene gel for 5 minutes may contribute significantly to the increased efficacy of therapy. ${ }^{11}$

In terms of safety, our study shows that adapalene has a comparatively better safety profile, only $2.1 \%$ patients treated with adapalene reported dryness whereas those treated with benzoyl peroxide-clindamycin combination reported dryness $(2.2 \%)$ and irritation $(2.2 \%)$. In a similar study done by Persy $\mathrm{SH}$, it was demonstrated that the incidence of adverse events was $24 \%$ in the patients treated with adapalene. The most common ones were burning, dryness, itching, irritation and erythema. ${ }^{6}$

Therefore, finally to conclude, adapalene has got similar efficacy and is comparatively better tolerated than benzoyl peroxide-clindamycin combination, thus adapalene alone can be used for the treatment of mild to moderate acne vulgaris like benzoyl peroxideclindamycin combination, whereas severe inflammatory lesions of acne can be topically treated with combination of either adapalene and clindamycin or combination of benzoyl peroxide and clindamycin along with the systemic therapy as suggested by previous studies.

\section{ACKNOWLEDGEMENTS}

Authors would like to thanks to the faculty and staff of department of Dermatology for their support in this study.

\author{
Funding: No funding sources \\ Conflict of interest: None declared \\ Ethical approval: The study was approved by the \\ Institutional Ethics Committee
}




\section{REFERENCES}

1. Emil A. Tanghetti. The role of inflammation in the pathology of acne. J Clin Aesthet Dermatol. 2013;6:27-35.

2. Selway J. The psychosocial impact of acne and rosacea. Adv Stud Nurs. 2005;3:239-43.

3. Reddy NB, Nandimath MK. Comparison of clinical efficacy of topical clindamycin with adapalene and adapalene alone in treatment of mild to moderate facial acne vulgaris. Int $J$ Pharm Bio Sci. 2013;4:1079-88.

4. Rathi SK. Acne vulgaris treatment: The current scenario. Indian J Dermatol. 2011;56:7-13.

5. Dutil M. Benzoyl peroxide: enhancing antibiotic efficacy in acne management. Skin Therapy Lett. 2010;15:5-7.

6. Persy SH. Safety and efficacy of adapalene gel $0.1 \%$ in acne vulgaris: results of a post-marketing surveillance study. Indian J Dermatol Venereol Leprol. 2003;69:277-80.

7. Balaji A, Kumari R, Thappa DM. Scoring systems in acne vulgaris. Indian J Dermatol Venereol Leprol. 2009;75:323-6.

8. Choudhury S, Chatterjee S, Sarkar DK, Dutta RN. Efficacy and safety of topical nadifloxacin and benzoyl peroxide versus clindamycin and benzoyl peroxide in acne vulgaris: a randomized controlled trial. Indian J Pharmacol. 2011;43:628-31.

9. Ray C, Trivedi P, Sharma V. Acne and its treatment lines. Int J Res Pharma Bio. 2013;3:1-16.

10. Kraft J, Freiman A. Management of acne. CMAJ. 2011;183:E430-435.

11. Jain GK, Ahmed FJ. Adapalene pretreatment increases follicular penetration of clindamycin: In vitro and in vivo studies. Indian J Dermatol Venereol Leprol. 2007;73:326-9.
12. Prasad S, Mukhopadhyay A, Kubavat A, Kelkar A, Modi A, Swarnkar B, et al. Efficacy and safety of a nano-emulsion gel formulation of adapalene $0.1 \%$ and clindamycin $1 \%$ combination in acne vulgaris: a randomized, open label, active-controlled, multicentric, phase IV clinical trial. Indian J Dermatolo Venereol Leprol. 2012;78:459-67.

13. Cunliffe WJ, Danby FW, Dunlap F, Gold MH, Gratton D, Greenspan A. Randomised, controlled trial of the efficacy and safety of adapalene gel $0.1 \%$ and tretinoin cream $0.05 \%$ in patients with acne vulgaris. Eur J Dermatol. 2002;12:350-4.

14. Toole JW, Lockhart L, Potrebka J, Bowman JP, Novack GD. Comparative irritancy study among retinoid creams and gels. J Cutan Med Surg. 1999;3:298-301.

15. Egan N, Loesche C, Baker M. Randomized, controlled, bilateral (split-face) comparison trial of the tolerability and patient preference of adapalene gel $0.1 \%$ and tretinoin microsphere gel $0.1 \%$ for the treatment of acne vulgaris. Cutis. 2001;68:20-4.

16. Ioannides D, Reigopoulos D, Katsambas A. Topical adapalene gel $0.1 \%$ versus. isotretinoin gel $0.05 \%$ in the treatment of acne vulgaris: a randomized openlabel clinical trial. Br J Dermatol. 2002;147:523-7.

17. Ghoshal L, Banerjee S, Ghosh SK, Gangopadhyay DN, Jana S. Comparative evaluation of effectiveness of adapalene and azithromycin, alone or in combination, in acne vulgaris. Indian $\mathrm{J}$ Dermatol. 2007;52:179-83.

18. Langner A, Chu A, Goulden V, Ambroziak M. A randomized, single-blind comparison of topical clindamycin + benzoyl peroxide and adapalene in the treatment of mild to moderate facial acne vulgaris. $\mathrm{Br}$ J Dermatol. 2008;158:122-9.

Cite this article as: Dubey $\mathrm{A}$, Amane $\mathrm{H}$. Comparison of efficacy and safety of adapalene and benzoyl peroxide-clindamycin combination in the topical treatment of acne vulgaris. Int J Basic Clin Pharmacol 2016;5:1727-32. 